\title{
The inflammatory response and neuronal injury in Streptococcus suis meningitis
}

Jana Seele $e^{1,2^{*}+} \mathbb{D}$, Simone C. Tauber ${ }^{3+}$, Stephanie Bunkowski ${ }^{1}$, Christoph G. Baums ${ }^{4}$, Peter Valentin-Weigand ${ }^{5}$, Nicole de Buhr ${ }^{6,7}$, Andreas Beineke ${ }^{8}$, Asparouh I. $\| l i e v^{9}$, Wolfgang Brück ${ }^{1}$ and Roland Nau ${ }^{1,2}$

\begin{abstract}
Background: Many of the currently used models of bacterial meningitis have limitations due to direct inoculation of pathogens into the cerebrospinal fluid or brain and a relatively insensitive assessment of long-term sequelae. The present study evaluates the utility of a Streptococcus (S.) suis intranasal infection model for the investigation of experimental therapies in meningitis.

Methods: We examined the brains of 10 piglets with S. suis meningitis as well as 14 control piglets by histology, immunohistochemistry and in-situ tailing for morphological alterations in the hippocampal dentate gyrus and microglial activation in the neocortex.

Results: In piglets with meningitis, the density of apoptotic neurons was significantly higher than in control piglets. Moreover, scoring of microglial morphology revealed a significant activation of these cells during meningitis. The slight increase in the density of dividing cells, young neurons and microglia observed in piglets suffering from meningitis was not statistically significant, probably because of the short time frame between onset of clinical signs and organ sampling.

Conclusions: The morphological changes found during S. suis meningitis are in accordance with abnormalities in other animal models and human autopsy cases. Therefore, the pig should be considered as a model for evaluating effects of experimental therapeutic approaches on neurological function in bacterial meningitis.
\end{abstract}

Keywords: Streptococcus suis, Pig model, Meningitis, Intranasal infection, Immunohistochemistry

\section{Background}

Streptococcus $($ S.) suis is an important pathogen in veterinary medicine. Prevention and treatment of S. suis infections contribute substantially to the high rate of antibiotic consumption in the pig producing industry [1]. More than $50 \%$ of the cases in pigs occur below the age of 12 weeks [2]. S. suis can also affect humans. Transmission to humans usually occurs by close contact with sick or asymptomatic carrier pigs or contaminated food. Most human infections are sporadic, but outbreaks took place particularly in Southeast Asia. S. suis is the most frequent cause of human bacterial meningitis in

\footnotetext{
* Correspondence: jana_seele@gmx.de

†Jana Seele and Simone C. Tauber contributed equally to this work.

'Department of Neuropathology, University Medical Center Göttingen,

Georg-August-University Göttingen, Göttingen, Germany

${ }^{2}$ Department of Geriatrics, Evangelisches Krankenhaus Göttingen-Weende,

Göttingen, Germany

Full list of author information is available at the end of the article
}

pork-consuming and pig-breeding countries in this area [3]. Both in pigs and humans, S. suis can cause meningitis, septicemia, endocarditis, arthritis, and septic shock, with a high mortality. Meningitis and septicemia are the most frequent clinical disease entities in humans [4]. The fatality rate in adult humans is approximately $13 \%$, and the most frequent long-term sequelae are hearing loss (39\%) and vestibular dysfunction (23\%) [5].

Many animal models used to study the pathophysiology of bacterial meningitis and to assess the effect of experimental therapeutic approaches on outcome have two main shortcomings: 1 . Bacteria are often injected directly into the cerebrospinal fluid (CSF) or brain [6-9], because with few exceptions [10], intranasal or intravenous modes of administration of bacteria do not cause meningitis in rates high enough to be suitable for experimental studies. 2. The neuropsychological assessment of long-term sequelae, particularly in mice, but also in rats, is not very

(c) The Author(s). 2018 Open Access This article is distributed under the terms of the Creative Commons Attribution 4.0 International License (http://creativecommons.org/licenses/by/4.0/), which permits unrestricted use, distribution, and 
sensitive to detect deficits. S. suis meningitis in pigs as a model may overcome these shortcomings, since infection usually is induced by intravenous injection or intranasal inoculation of $S$. suis which closely mimics the conditions in human disease [11]. From the bloodstream, these pathogens most likely enter the CSF via the choroid plexus [12]. In terms of size, the pig brain corresponds better to humans compared to the rodent brain. Moreover, genetics, anatomy and physiology of the pig are closely related to humans [13]. For the assessment of long-term motor and neuropsychologic sequelae in pigs, several sensitive and valid test batteries are available $[14,15]$. For these reasons, the pig model of $S$. suis meningitis may be preferable to all rodent models to study the effect of experimental therapeutic approaches on neurological function in meningitis.

Morphological abnormalities in human autopsy cases and radiological studies as well as animal models of bacterial meningitis are well characterized [7, 8, 16-23]. The present study further evaluates the utility of the piglet model for the study of experimental therapies in bacterial meningitis. We aimed at assessing whether the morphological alterations seen in the brains of piglets with S. suis meningitis are comparable to the abnormalities observed in human autopsy cases and in rodent models of bacterial meningitis.

\section{Methods}

\section{S. suis infection model}

In this study, brains of piglets from partially published experiments were analysed [24, 25]. Briefly, 35 German Landrace piglets purchased from one breeder at ages of 4 to 9 weeks, free of suilysin $(s l y)_{+}$, muramidase-released protein $(m r p)+$, extracellular factor $($ epf $)+$ and capsular serotype (cps) $2+S$. suis strains, were intranasally infected with approximately $1 \times 10^{9}$ colony forming units (CFU) $S$. suis serotype 2 strain 10 (sly+, mrp+, epf+) after decreasing the colonization resistance of the nasal mucosa by intranasal treatment with $1 \%$ acetic acid [26]. Piglets were cared for in accordance with the principles outlined in the European Convention for the Protection of Vertebrate Animals Used for Experimental and Other Scientific Purposes. The animal experiments were approved by the Committee on Animal Experiments of the Lower Saxony State Office for Consumer Protection, Food Safety and Animal Protection (permit no. 33.14-42,502-04-12/0965 and 33.9-42,50204-12/0965). In the case of high fever $\left(\geq 40.5{ }^{\circ} \mathrm{C}\right)$, apathy and anorexia persisting over 36 hours (h) as well as in all cases with clinical signs of acute polyarthritis or severe meningitis, animals were anaesthetized with $2 \mathrm{mg} / \mathrm{kg}$ azaperon (Stresnil; Janssen, Neuss, Germany) and $10 \mathrm{mg} / \mathrm{kg}$ ketamine-hydrochloride (Ursotamin; Serumwerk, Bernburg, Germany) intramuscularly. Thereafter, they were sacrificed by injection of $100 \mathrm{mg} / \mathrm{kg}$ pentobarbital sodium (Release; Wirtschaftsgenossenschaft deutscher Tierärzte eG, Garbsen, Germany) into the marginal ear vein. The interval between infection and termination of the experiment for animals with meningitis is depicted in Table 1.

Out of 35 infected piglets, 10 animals developed meningitis and were classified as experimental group. A total of 14 piglets that showed no inflammation in the CNS and no gross morphological abnormalities in all organs investigated, or had only histopathological alterations in one organ other than the brain, and in that organ, S. suis was not detected, were included in the control group. Animals were excluded from the analysis, as they

Table 1 Clinical data of piglets with meningitis

\begin{tabular}{|c|c|c|c|c|c|c|c|}
\hline $\begin{array}{l}\text { animal } \\
\text { no. }\end{array}$ & lesion $^{a}$ & $\begin{array}{l}\text { intensity } \\
\text { of the } \\
\text { lesion }\end{array}$ & $\begin{array}{l}\text { semiquantitative } \\
\text { bacterial load }{ }^{\text {b }} \text { in } \\
\text { CSF }\end{array}$ & $\begin{array}{l}\text { semiquantitative } \\
\text { bacterial load }{ }^{\text {b }} \text { in } \\
\text { brain swabs }\end{array}$ & $\begin{array}{l}\text { age at time point } \\
\text { of infection (in } \\
\text { weeks) }\end{array}$ & $\begin{array}{l}\text { interval between infection } \\
\text { and first signs of sickness } \\
\text { (days) }^{c}\end{array}$ & $\begin{array}{l}\text { interval between infection } \\
\text { and termination of the } \\
\text { experiment (days) }\end{array}$ \\
\hline 1 & $A$ & mild & +++ & +++ & 4 & 1 & 1.5 \\
\hline 2 & $B ; D$ & severe & +++ & + & 4 & 1.5 & 3 \\
\hline 3 & $B ; D$ & severe & +++ & ++ & 4 & 4 & 5.5 \\
\hline 4 & B & severe & +++ & + & 7 & 2.5 & 3.5 \\
\hline 5 & B & severe & - & +++ & 9 & 1 & 2.5 \\
\hline 6 & A & mild & ++ & ++ & 9 & 1 & 3 \\
\hline 7 & $B$ & severe & ++ & + & 9 & 6.5 & 7.5 \\
\hline 8 & C & severe & +++ & +++ & 9 & 2.5 & 3.5 \\
\hline 9 & $B$ & severe & +++ & + & 9 & 6.5 & 7.5 \\
\hline 10 & B & severe & - & +++ & 9 & 1 & 2.5 \\
\hline
\end{tabular}

${ }^{\mathrm{a}} \mathrm{A}=$ focal purulent meningitis

$B=$ diffuse purulent meningitis

$C=$ multi-focal purulent meningitis

$D=$ encephalitic involvement of the brain tissue

bacterial load: $+<50$ colonies; $++\geq 50$ colonies; $+++\geq 500$ colonies per plate; - no detection of the infection strain

'first signs of sickness such as fever $\left(\geq 40.2^{\circ} \mathrm{C}\right)$, apathy, convulsions, lameness and anorexia 
showed histopathological alterations in more than one organ and/or bacteria were detected in the respective organ(s). These piglets had pleuritis, peritonitis, synovialitis, splenitis, hepatitis, pneumonia or endocarditis. The 14 control piglets were screened negative for S. suis serotype 2 strain 10 (with exception of the tonsils). All surviving piglets including the control piglets were killed 14-15 days post infection (dpi). Thereafter, each animal was autopsied according to the same protocol, which included predefined collection of samples for histological and bacteriological investigations. Purulent inflammations were scored by blinded investigators as described previously [26]. The following lesions were detected in the piglets by histological investigations $(n=35$; some piglets had more than one histopathological lesion): meningitis $(n=10,28.6 \%$; of which 2 piglets showed also encephalitic involvement of the brain tissue), pleuritis or peritonitis $(n=7,20.0 \%)$, synovialitis $(n=5,14.3 \%)$, splenitis or hepatitis $(n=8,22.9 \%)$, pneumonia $(n=15$, $42.9 \%)$ and endocarditis $(n=1,2.9 \%)$. Eight piglets (22.9\%) did not develop histopathological lesions (with exception of a minimal accumulation of neutrophils in the red pulp of the spleen). For assessment of the semiquantitative bacterial loads $50 \mu \mathrm{l} \mathrm{CSF}$ and the brain swab of each animal were plated on Columbia sheep blood agar and incubated for $24 \mathrm{~h}$ at $37^{\circ} \mathrm{C}(+<50$ colonies; + $+\geq 50$ colonies; $+++\geq 500$ colonies per plate).

Brain sections of the hippocampal formation, the frontal cortex and the cerebellum of 10 piglets with meningitis confirmed by histopathological analysis and 14 control piglets from the same infection experiments were used for further analysis by histology, immunohistochemistry and in-situ tailing. Inflammation of meninges and brain tissue was evaluated by haematoxylin and eosin (HE) and chloroacetate esterase (CAE) staining of $2 \mu \mathrm{m}$ sections from the frontal cortex, the cerebellum and the hippocampal formation. HE stained sections were also used to detect ischemic lesions.

\section{Immunohistochemistry and in-situ tailing}

Two $\mu \mathrm{m}$ thick brain sections of the hippocampal formation were deparaffinised, microwaved $(5 \times 3 \mathrm{~min} ; 800 \mathrm{~W})$, incubated in citric acid buffer $(10 \mathrm{mmol} / \mathrm{L}, \mathrm{pH} 6.0)$ for 10 min and then blocked with $10 \%$ fetal calf serum (FCS) in phosphate-buffered saline (PBS) for $30 \mathrm{~min}$. All primary antibodies were applied at the concentrations indicated below and incubated overnight at $4{ }^{\circ} \mathrm{C}$ in PBS. Brain slices were stained for the detection of proliferating cells with a monoclonal mouse anti-PCNA (proliferating cell nuclear antigen) antibody (dilution 1:200; Chemicon, Temecula, CA), microglia were detected using a polyclonal rabbit anti-Iba-1 (ionized calcium binding adaptor molecule 1) (1:400, Wako, Neuss, Germany) antibody. Astrocytes were visualized by a polyclonal rabbit anti-GFAP (glial fibrillary acidic protein) antibody (1:1000; Dako, Hamburg, Germany), and axonal injury was investigated with a monoclonal mouse antibody against APP (amyloid beta precursor protein) (1:2000; Chemicon) as described previously by Tauber et al. [27]. For staining of young post-mitotic neurons an antibody directed against calretinin was used (1:1000, Swant, Bellinzona, Switzerland) [28]. For detection of S. suis antigen brain sections were blocked with $2 \%$ bovine serum albumin (BSA) plus $0.2 \%$ Triton X-100 in PBS for 20 min and then incubated with a rabbit anti-S. suis antibody (1:250). Secondary biotinylated sheep anti-mouse antibodies (1:200; Amersham, Buckinghamshire, UK) or biotinylated donkey anti-rabbit antibodies (1200; GE Healthcare, Buckinghamshire, UK) diluted in PBS, followed by addition of avidin-biotin peroxidase complex (Vector Laboratories, Burlingame, CA), and diaminobenzidine (Roche, Mannheim, Germany) as chromogenic substrates were used for visualization. Binding of the APP antibody was visualized using the alkaline phosphatase/anti-alkaline phosphatase method with New Fuchsin as the chromogenic substrate. Brain sections were counterstained with hemalum (Merck, Darmstadt, Germany). Isotypic antibodies and brain sections incubated with secondary antibodies in the absence of primary antibodies served as controls as described by Tauber et al. [27]. After incubation with primary and secondary antibodies samples were washed with PBS.

Apoptotic neurons in the dentate gyrus of the hippocampal formation $[7,8,20,27]$ and granulocytes in meningeal infiltrates $[29,30]$ were identified by in-situ tailing (IST) and morphology (condensed, shrunken nuclei, condensed and shrunken eosinophilic cytoplasm) [31]. The sections were counterstained with nuclear fast red-aluminiumhydroxide (Roche, Mannheim, Germany).

Representative results of stained brain sections are shown in Fig. 1.

\section{Microscopy and statistical analysis}

To quantify cells in the dentate gyrus, only immunoreactive cells in the granule cell layer and the subgranular zone (SGZ) were counted [27]. Analysis Software Imaging System (microscope BX51; Olympus; software AnalySIS 3.2; Soft Imaging System GmbH, Münster, Germany) was used to measure the area of the dentate granule cell layer. For analysis of microglial activation morphology, we followed the activation steps identified and described by Kreutzberg [32] $(0=$ fully resting microglia with multiple branches; 1 $=$ mix between resting and mildly activated microglia, demonstrating shortened processes with increased thickness; 2 = mildly activated microglia with shortened processes with increased thickness; $3=\operatorname{mix}$ between mildly and strongly activated ameboid microglia without processes; $4=$ ameboid microglia without processes) in the neocortical layers I-III. 


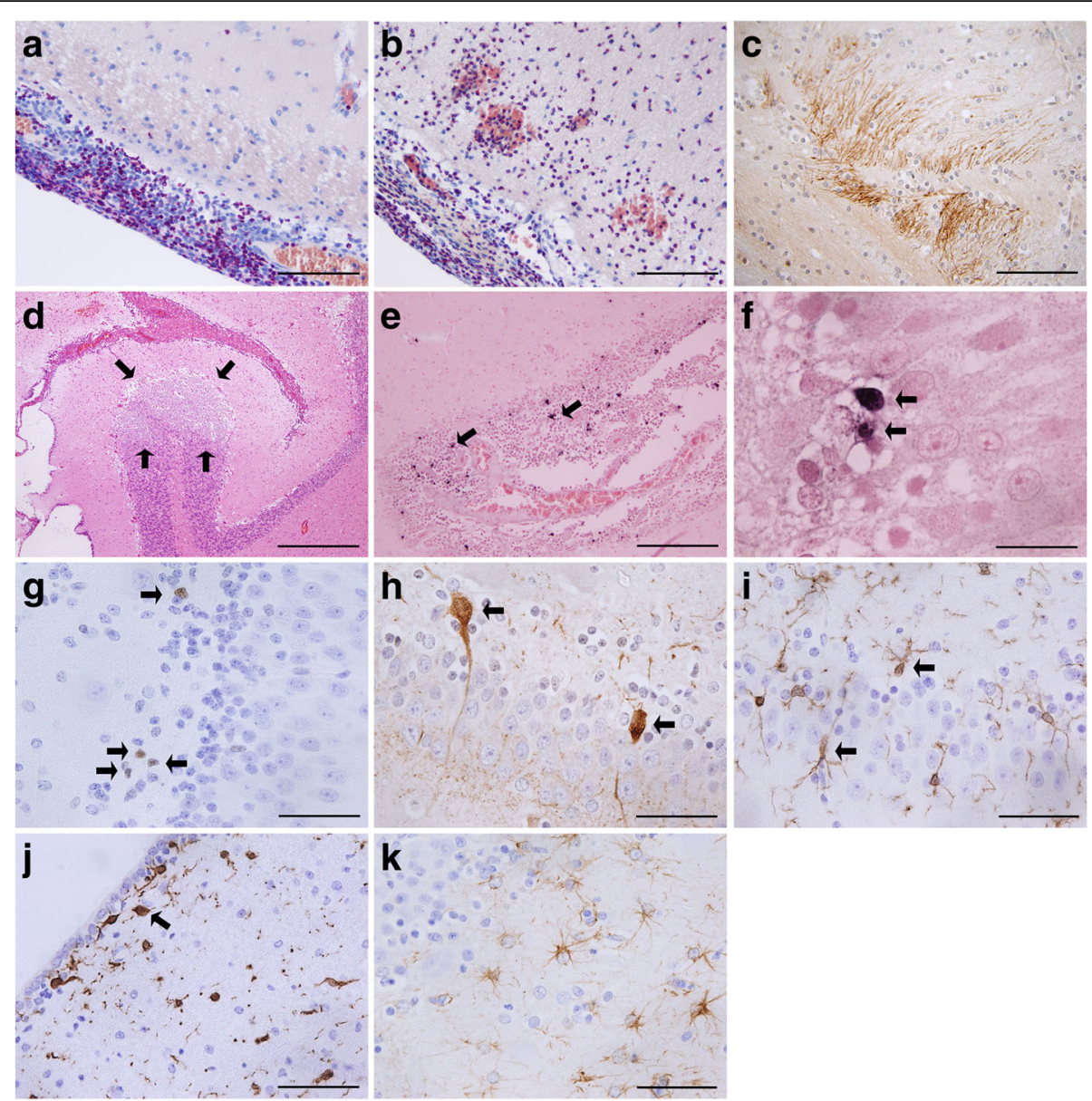

Fig. 1 Histology, immunohistochemistry and in-situ tailing of brain sections from piglets suffering from S. suis meningitis. Chloroacetate esterase (CAE)-staining of a frontal cortex section of a piglet suffering from meningitis (a; animal no. 10) or haemorrhagic meningoencephalitis (b; animal no. 3). Neutrophilic granulocytes and some monocytes are stained violet. Axonal damage was visualized by an anti-amyloid beta precursor protein (APP) antibody (brown) (c; animal no. 3) and was observed only in one piglet. Ischaemic injuries were visualized by H\&E staining and also found only in one animal (d; animal no. 3). The densities of apoptotic leukocytes in meningeal infiltrates (e; animal no. 4) and granule cells in the hippocampal dentate gyrus (f; animal no. 5) were assessed by in-situ tailing (dark violet) and morphology. Proliferation of neural progenitor cells in the dentate gyrus was detected by staining of the proliferating cell nuclear antigen (PCNA) (brown) ( $\mathbf{g}$; animal no. 4). Young neurons were stained with an anti-calretinin antibody (brown) (h; animal no. 5). Microglia were detected by an anti-ionized calcium binding adaptor molecule 1 (Iba-1) antibody (brown) (animal no. 9). Microglia were slightly activated in the dentate gyrus (i) and highly activated (j) in close proximity to the CSF compartments. Astrocytes were stained with an anti-glial fibrillary acidic protein (GFAP) antibody (brown) (k; animal no. 4). The horizontal bars indicate $100 \mu \mathrm{m}(\mathbf{a}-\mathbf{c}), 500 \mu \mathrm{m}(\mathbf{d}), 200 \mu \mathrm{m}(\mathbf{e}), 20 \mu \mathrm{m}(\mathbf{f})$ and $50 \mu \mathrm{m}(\mathbf{g}-\mathbf{k})$

Data were expressed as medians and scatter dot plots and compared by two-tailed Mann-Whitney U-test. Statistical analyses were carried out using GraphPad Prism (GraphPad 6 Software, San Diego, CA, USA). Probabilities lower than 0.05 were considered statistically significant $\left(* p<0.05\right.$; $\left.{ }^{* * * * *} p<0.001\right)$.

\section{Results}

In this study the brains of piglets which had been infected intranasally with S. suis serotype 2 strain 10 were analysed for leukocyte infiltration, microglial and astrocyte density, ischemia, axonal injury, neuronal apoptosis and neural proliferation in the dentate gyrus of the hippocampal formation as well as microglial activation in the neocortical layers I-III. At autopsy, piglets showed severe diffuse purulent meningitis (5 cases) (Fig. 1a), severe diffuse purulent meningitis with encephalitic involvement of the brain tissue (2 cases) (Fig. 1b), severe multi-focal purulent meningitis (1 case) and mild focal purulent meningitis (2 cases). Axonal damage and ischaemic injury was found in one case (Fig. 1c and d, respectively). Piglets that developed meningitis showed typical signs of illness starting from day 1 until 6.5 days post infection (median time 2 days). Depending on the severity of clinical signs, the piglets were euthanized 0.5-2 days (median time 1.25 days) after onset of the first clinical signs of illness. In the meningitis group $S$. suis was detected by bacteriological cultures and PCR 
analysis in 8 out of 10 CSF samples and in all brain swabs (Table 1). The control group consisted of 14 piglets that had been intranasally infected but which lacked any S. suis-associated lesions in the brain and were negative for the infection strain in the bacteriological screenings (with exception of the tonsils).

The hippocampal formations of the piglets were analysed by immunohistochemistry and in-situ tailing for morphological alterations. An increased density of apoptotic neurons in the hippocampal dentate gyrus (median $=4.45 / \mathrm{mm}^{2}$ ) in piglets with meningitis was measured compared to control piglets without signs of CNS inflammation $\quad\left(\right.$ median $\left.=1.14 / \mathrm{mm}^{2}\right) \quad(p=0.017)$ (Fig. 2a). Proliferation in the granule cell layer and the subgranular zone of the hippocampal dentate gyrus as a sign of regeneration, analysed by counting cells positive for PCNA, was slightly increased in the meningitis group but did not differ significantly from the control group ( $p$ $=0.4$ ) (Fig. 2b). A tendency towards an increased neurogenesis during meningitis was detectable as assessed by the density of calretinin-positive cells, but the difference also did not reach statistical significance $(p=0.19)$ (Fig. 2c). Scoring of the morphology of microglia revealed a strong activation of these cells in the meningitis group and only a slight activation in the control group in layer I-III in the neocortex (Fig. 2d) $(p=0.0008)$. In line with these results, strong microglial activation was seen close to the CSF compartments in piglets suffering from meningitis (Fig. 1j). However, the number of microglial cells did not differ significantly in both groups (Fig. 2e) $(p=0.44)$. We did not see astrocytosis in the hippocampal dentate gyrus $(p=0.99$, piglets with meningitis versus control piglets) (Fig. 2f). In the meningitis group, S. suis and S. suis antigens were detected by a S. suis-specific antibody in meningeal infiltrates (Fig. 3a) and in the cytoplasm of phagocytes, respectively (Fig. 3b).

\section{Discussion}

In the present study we aimed at assessing whether the morphological alterations seen in the brains of piglets with $S$. suis meningitis are comparable to the abnormalities observed in human autopsy cases and in rodent models of bacterial meningitis. All piglets analysed in this study were infected intranasally with S. suis. Piglets which were selected as controls did not show infection-associated lesions of the CNS when investigated histopathologically and were negative in the bacteriological screening for the infection strain in CSF as well as in punctures of the tarsal joints, brain, peritoneal, pleural, and pericardial cavities, cranial lobe of the lung, liver and spleen. Animals were excluded from the analysis as they showed histopathological alterations in more than one organ other than the brain and/or

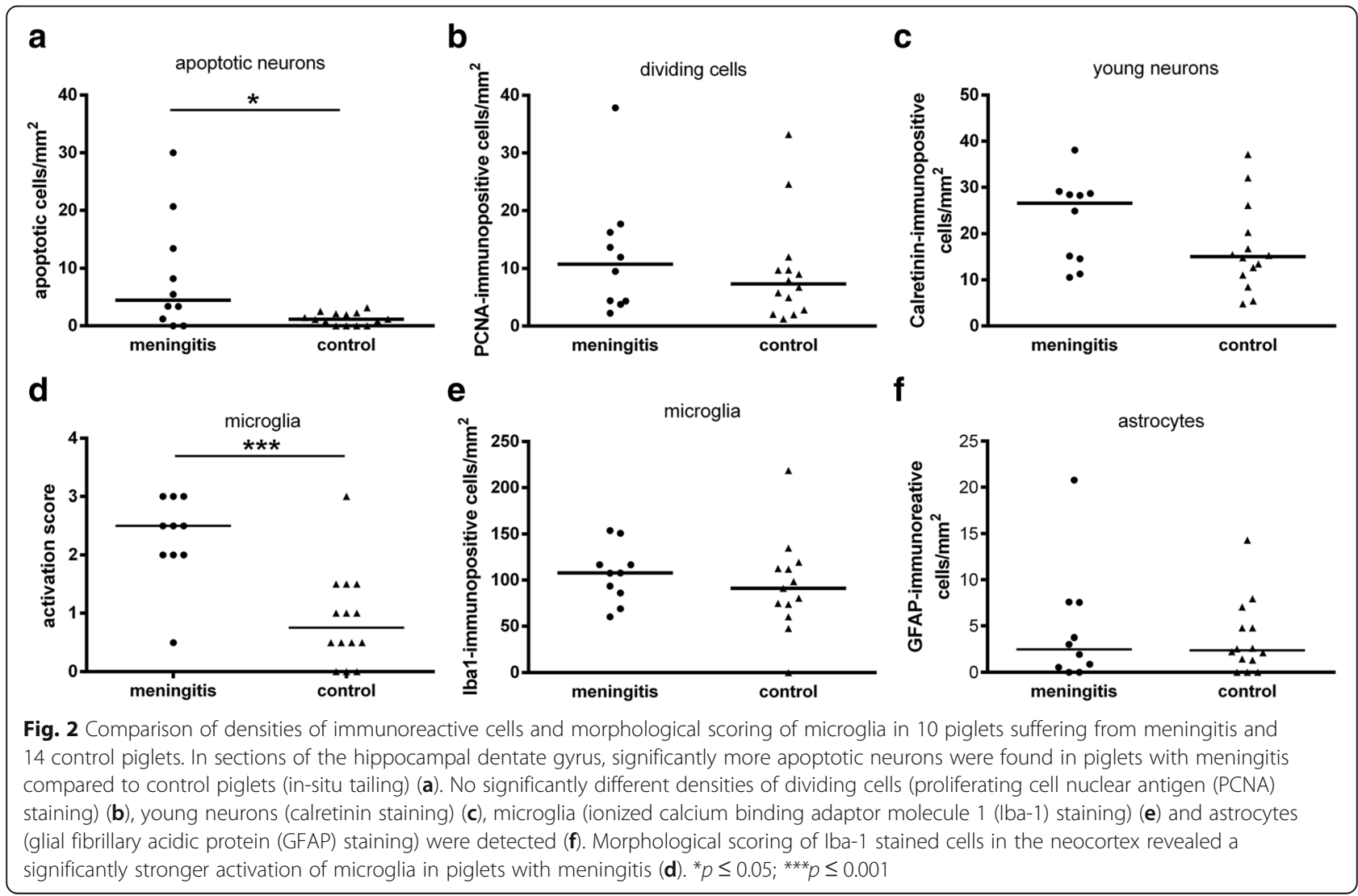




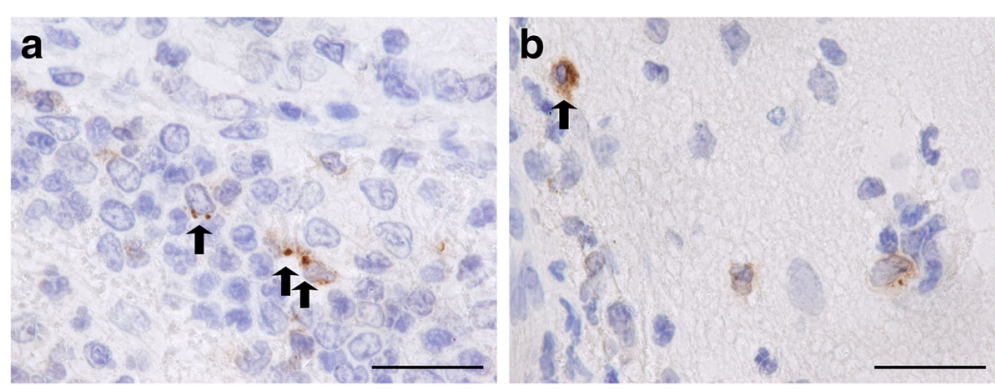

Fig. 3 Detection of S. suis and S. suis antigens in brain sections of piglets with meningitis. S. suis and S. suis antigens (brown) were visualized by a S. suis-specific antibody in meningeal infiltrates as indicated by arrows (animal no. 5) (a) and in the cytoplasm of phagocytes (animal no.2) (b). The horizontal bars indicate $20 \mu \mathrm{m}$

because bacteria were detected in the respective organ(s). All piglets used in the experiments were of similar age and the same breed, but from different litters. It is known that a substantial within-breed variability exists in pigs [33] which may explain the different disease outcomes. Moreover, the course of the disease depends on the immune status of the animals, which is shaped by genetics, transferred maternal immunity (at least in the first weeks after birth), health status and environmental factors [34, 35].

Meningitis is a typical feature of S. suis CNS infections, whereas encephalitis (i.e., involvement of brain tissue) is described less frequently. In the present study, we observed meningitis in 8 out of 10 piglets with infection of the CNS and in two out of 10 piglets a strong meningoencephalitis. Similarly, in humans infected with S. suis, the main pathology is meningitis followed by sepsis, arthritis, endocarditis, and endophthalmitis [5]. Encephalitic involvement of the brain parenchyma was described less frequently in patients $[36,37]$. In an experimental model using the Chinese $S$. suis serotype 2 strain SC19, intranasal inoculation of pigs resulted in meningoencephalitis in all animals with CNS infection [38]. Similarly, Sanford [39] reported meningoencephalitis and meningoencephalomyelitis in all 53 investigated cases of naturally occurring S. suis CNS infections in pigs. In contrast, others found only meningitis after experimental infection [40-43]. Involvement of the brain tissue may depend on serotype [44], strain and (in experimental infections) on study design.

Inflammation of the CNS was observed in 10 out of 35 piglets $(28.6 \%)$ after intranasal inoculation of S. suis. In a murine colonization and infection model, meningitis was detected only in 1 out of 10 mice (without intranasal pretreatment with acetic acid) and in none of 32 mice in which the colonization resistance of the nasal mucosa was reduced by intranasal administration of $1 \%$ acetic acid, even though the same $S$. suis strain and a five times higher infection dose $\left(5 \times 10^{9} \mathrm{CFU} /\right.$ mouse $)$ was used [45]. In a murine pneumococcal infection model meningitis rates of $50 \%$ were observed after intranasal administration of hyaluronidase prior infection [10].

In most animal models, and in human autopsy cases, neuronal injury and neural repair as well as microglial proliferation and astrocytosis are frequently detectable in the hippocampal formation during meningitis and meningoencephalitis $[7,8,17,20,27,46-50]$. Therefore, we focused on morphological changes in this brain region during CNS infection with $S$. suis. In piglets suffering from meningitis, we observed an increase in apoptotic neurons in the dentate gyrus compared to control piglets. These results are in line with morphological abnormalities in a rabbit model of pneumococcal meningitis $[8,47]$, in neonatal and adult rat models $[7,51]$ and in human autopsy cases [20]. However, the number of apoptotic cells was in general lower in the pig model (meningitis group: $0-30$ apoptotic cells $/ \mathrm{mm}^{2}$ vs. control group: $0-3$ apoptotic cells $/ \mathrm{mm}^{2}$ ) in contrast to the rabbit model (meningitis group: 227 (99/339) apoptotic cells $/ \mathrm{mm}^{2}$ vs. control group: 41 (37/45) apoptotic cells/ $\mathrm{mm}^{2}$, [median (25./75. quartile)]) [47] but comparable with a mouse model of pneumococcal meningitis (meningitis group: $71 \pm 29$ apoptotic cells $/ \mathrm{mm}^{2}$ vs. control group: $37 \pm 18$ cells $/ \mathrm{mm}^{2}$ ) [52]. The density of apoptotic dentate granular cells in our piglet model was similar to the density of neuronal apoptosis in human autopsy cases after death from meningitis [20]. Cytotoxic activity of the secreted cytolysin suilysin of $S$. suis may directly induce neuronal injury as demonstrated by Stringaris et al. for pneumolysin [53], the highly homologous protein of S. pneumoniae [54]. A further well described mechanism involved in neuronal damage is the activation of microglial cells. Different stimuli such as CpG-DNA [55]; LPS [56, 57], $\mathrm{Pam}_{3} \mathrm{CSK}_{4}$ [58] or beta-Amyloid [59, $60]$ were shown to activate microglia, causing neuronal damage. In addition, the gram-positive cell wall can activate microglia [61]. Scoring of the microglial morphology revealed a statistically significant activation of microglia in the meningitis group (Fig. 2d). However, we 
detected only a slight increase in microglial cell numbers in piglets with meningitis even though increased inflammation causes microglial proliferation in the human CNS $[27,48]$.

In the present study, we observed a tendency towards increased proliferation and neuronal differentiation during S. suis CNS infection as signs of regeneration. In humans, significant proliferation of progenitor cells in the hippocampal dentate granule cell layer and subgranular zone was observed during bacterial meningitis [17], septic metastatic encephalitis [49] and fungal meningoencephalitis [48]. Different animal models of pneumococcal CNS infection revealed similar results: neurogenesis peaked at day 2 post infection, and the difference between infected and uninfected mice reached statistical significance at day 6 after intracerebral infection (measured by density of BrdU-labeled cells in the subgranular layer of the dentate gyrus). Likewise, neurogenesis was significantly increased in rabbits $24 \mathrm{~h}$ after intracisternal infection with pneumococci [47] and in rats 7 days post infection [62]. In contrast to the mouse, rat and rabbit models [7, 47, 62-64], piglets were infected by intranasal inoculation which reflects the natural route of infection and were not treated with antibiotics.

The lack of significant changes in regard to neuronal proliferation and differentiation as well as astrocytosis and number of microglia, which are observed in human autopsy cases $[17,27,48]$, is most likely the result of the short period of time between the onset of clinical symptoms such as fever or apathy and organ sampling. In line with this hypothesis, axonal damage and ischaemic injury were only observed in one piglet, even though microbial compounds can cause axonal damage via stimulation of immune cells [65] and ischaemic injuries are observed in cases of human meningitis [21]. Piglets were killed as early as 12-48 h after onset of the first clinical signs (median interval $30 \mathrm{~h}$ ) due to reasons of animal welfare. An antibiotic treatment 12 or $24 \mathrm{~h}$ post infection [20,47] would be prerequisite for extending the survival time of piglets, and thus increase the likelihood of detecting more marked morphological changes.

Unlike in rodents, several sensitive and valid test batteries are available for the assessment of long-term motor and neuropsychologic sequelae in pigs $[14,15]$. In addition, the pig is considered to be an excellent model for studying infectious diseases of humans [13, 66]. Genetics, anatomy and physiology of pigs are closely related to humans. In regard to immunology, the porcine immune system closely resembles the human immune system for more than $80 \%$ of analyzed immunological parameters, in stark contrast to mice in which less than $10 \%$ of the parameters analyzed were more similar to humans (see review by Meurens et al. [13]).

\section{Conclusions}

The pig model of $S$. suis meningitis by intranasal infection appears to be most suitable for studying treatment options of bacterial meningitis. It has the advantage that it more closely resembles human meningitis than rodent models, as underlined by our findings that the brains of piglets showed the typical morphological alterations present in human autopsy cases. The lack of statistically significant differences of some parameters in the present study may be the consequence of the short duration of infection and of a mild inflammatory response in the control group due to the intranasal inoculation of bacteria. As shown in rodent infection models $[29,62,67$, 68] an antibiotic treatment can prolong survival and increase the chance of detecting stronger morphological alterations caused by infectious pathogens. Therefore, the pig should be considered as a model for evaluating the effects of experimental therapeutic approaches during CNS infections.

\section{Abbreviations \\ APP: Amyloid beta precursor protein; BSA: Bovine serum albumin; CAE: Chloroacetate esterase; CFU: Colony forming units; DPI: Days post infection; CNS: Central nervous system; CSF: Cerebrospinal fluid; epf: Extracellular factor; FCS: Fetal calf serum; GFAP: Glial fibrillary acidic protein; h: Hours; HE: Haematoxylin and eosin; Iba-1: Ionized calcium binding adaptor molecule-1; IST: In-situ tailing; mrp: Muramidase-released protein; PBS: Phosphate-buffered saline; PCNA: Proliferating cell nuclear antigen; S: Streptococcus; SGZ: Subgranular zone; sly: Suilysin}

\section{Acknowledgements}

We thank Cynthia Bunker for language editing.

\section{Funding}

This study was supported by the Niedersachsen Research Network on Neuroinfectiology of the Ministry of Science and Culture of Lower Saxony (N-RENNT) and the B. Braun-Stiftung. The funding bodies did not influence the design of the study, collection, analysis, and interpretation of data and in writing the manuscript.

\section{Availability of data and materials}

All data generated or analysed during this study are included in this published article [and its supplementary information files].

\section{Authors' contributions}

JS contributed to study design, conducted the animal experiments, took microscopic pictures, analyzed data and drafted the manuscript. SCT analyzed brain sections and related data and contributed to manuscript revision. SB conducted all stainings. CGB conducted animal experiments and contributed to manuscript revision. PW supported animal experiments and contributed to manuscript revision. NB supported animal experiments and contributed to manuscript revision. $A B$ and WB conducted histopathological analysis and revised the manuscript. All performed morphological scoring of microglia and revised the manuscript. RN conceived the study, took microscopic pictures and drafted the manuscript. All authors read and approved the final version of the manuscript.

\section{Ethics approval and consent to participate}

Piglets were cared for in accordance with the principles outlined in the European Convention for the Protection of Vertebrate Animals Used for Experimental and Other Scientific Purposes. The animal experiments were approved by the Committee on Animal Experiments of the Lower Saxony State Office for Consumer Protection, Food Safety and Animal Protection (permit no. 33.14-42,502-04-12/0965 and 33.9-42,502-04-12/0965). 


\section{Consent for publication}

Not applicable.

\section{Competing interests}

The authors declared that they have no competing.

\section{Publisher's Note}

Springer Nature remains neutral with regard to jurisdictional claims in published maps and institutional affiliations.

\section{Author details}

'Department of Neuropathology, University Medical Center Göttingen, Georg-August-University Göttingen, Göttingen, Germany. ${ }^{2}$ Department of Geriatrics, Evangelisches Krankenhaus Göttingen-Weende, Göttingen, Germany. ${ }^{3}$ Department of Neurology, RWTH University Hospital, Aachen, Germany. ${ }^{4}$ Institute for Bacteriology and Mycology, Center for Infectious Diseases, Faculty of Veterinary Medicine, University Leipzig, Leipzig, Germany. ${ }^{5}$ Institute for Microbiology, Center for Infection Medicine, University of Veterinary Medicine Hannover, Hannover, Germany. ${ }^{6}$ Department of Physiological Chemistry, Department of Infectious Diseases, University of Veterinary Medicine Hannover, Hannover, Germany. ${ }^{7}$ Research Center for Emerging Infections and Zoonoses (RIZ), University of Veterinary Medicine Hannover, Hannover, Germany. ${ }^{8}$ Department of Pathology, University of Veterinary Medicine Hannover, Hannover, Germany. ${ }^{9}$ Institute of Anatomy, University of Bern, Bern, Switzerland.

Received: 13 March 2018 Accepted: 22 June 2018

Published online: 03 July 2018

\section{References}

1. Seitz M, Valentin-Weigand P, Willenborg J. Use of antibiotics and antimicrobial resistance in veterinary medicine as exemplified by the swine pathogen Streptococcus suis. Curr Top Microbiol Immunol. 2016; 398:103-21

2. Reams RY, Glickman LT, Harrington DD, Bowersock TL, Thacker HL. Streptococcus suis infection in swine: a retrospective study of 256 cases. Part I. Epidemiologic factors and antibiotic susceptibility patterns. J Vet Diagn Investig. 1993:5(3):363-7.

3. van Samkar A, Brouwer MC, Schultsz C, van der Ende A, van de Beek D. Streptococcus suis meningitis: a systematic review and meta-analysis. PLoS Negl Trop Dis. 2015;9(10):e0004191. https://www.ncbi.nlm.nih.gov/pubmed/ ?term=ostergaard+leib+2010

4. Lun ZR, Wang $Q P$, Chen $X G$, Li $A X$, Zhu $X Q$. Streptococcus suis: an emerging zoonotic pathogen. Lancet Infect Dis. 2007;7(3):201-9.

5. Huong VT, Ha N, Huy NT, Horby P, Nghia HD, Thiem VD, et al. Epidemiology, clinical manifestations, and outcomes of Streptococcus suis infection in humans. Emerg Infect Dis. 2014;20(7):1105-14.

6. Pfister HW, Kodel U, Dirnagl U, Haberl RL, Ruckdeschel G, Einhaupl KM. Effect of catalase on regional cerebral blood flow and brain edema during the early phase of experimental pneumococcal meningitis. J Infect Dis. 1992;166(6):1442-5.

7. Leib SL, Kim YS, Chow LL, Sheldon RA, Tauber MG. Reactive oxygen intermediates contribute to necrotic and apoptotic neuronal injury in an infant rat model of bacterial meningitis due to group B streptococci. J Clin Invest. 1996;98(11):2632-9.

8. Zysk G, Bruck W, Gerber J, Bruck Y, Prange HW, Nau R. Anti-inflammatory treatment influences neuronal apoptotic cell death in the dentate gyrus in experimental pneumococcal meningitis. J Neuropathol Exp Neurol. 1996; 55(6):722-8.

9. Gerber J, Raivich G, Wellmer A, Noeske C, Kunst T, Werner A, et al. A mouse model of Streptococcus pneumoniae meningitis mimicking several features of human disease. Acta Neuropathol. 2001;101(5):499-508.

10. Zwijnenburg PJ, van der Poll T, Florquin S, van Deventer SJ, Roord JJ, van Furth AM. Experimental pneumococcal meningitis in mice: a model of intranasal infection. J Infect Dis. 2001;183(7):1143-6.

11. Beineke A, Bennecke K, Neis C, Schroder C, Waldmann KH, Baumgartner W et al. Comparative evaluation of virulence and pathology of Streptococcus suis serotypes 2 and 9 in experimentally infected growers. Vet Microbiol. 2008;128(3-4):423-30.

12. Tenenbaum T, Papandreou T, Gellrich D, Friedrichs U, Seibt A, Adam R, et al. Polar bacterial invasion and translocation of Streptococcus suis across the blood-cerebrospinal fluid barrier in vitro. Cell Microbiol. 2009:11(2):323-36

13. Meurens F, Summerfield A, Nauwynck H, Saif L, Gerdts V. The pig: a model for human infectious diseases. Trends Microbiol. 2012;20(1):50-7.

14. Naim MY, Friess S, Smith C, Ralston J, Ryall K, Helfaer MA, et al. Folic acid enhances early functional recovery in a piglet model of pediatric head injury. Dev Neurosci. 2010;32(5-6):466-79.

15. Rytych JL, Elmore MR, Burton MD, Conrad MS, Donovan SM, Dilger RN, et al. Early life iron deficiency impairs spatial cognition in neonatal piglets. J Nutr. 2012;142(11):2050-6

16. Kastenbauer S, Pfister HW. Pneumococcal meningitis in adults: spectrum of complications and prognostic factors in a series of 87 cases. Brain. 2003; 126(Pt 5):1015-25.

17. Gerber J, Tauber SC, Armbrecht I, Schmidt H, Bruck W, Nau R. Increased neuronal proliferation in human bacterial meningitis. Neurology. 2009; 73(13):1026-32.

18. Blaser C, Wittwer M, Grandgirard D, Leib SL. Adjunctive dexamethasone affects the expression of genes related to inflammation, neurogenesis and apoptosis in infant rat pneumococcal meningitis. PLoS One. 2011; 6(3):e17840

19. Wippel C, Maurer J, Fortsch C, Hupp S, Bohl A, Ma J, et al. Bacterial cytolysin during meningitis disrupts the regulation of glutamate in the brain, leading to synaptic damage. PLoS Pathog. 2013;9(6):e1003380.

20. Nau R, Soto A, Bruck W. Apoptosis of neurons in the dentate gyrus in humans suffering from bacterial meningitis. J Neuropathol Exp Neurol. 1999; 58(3):265-74.

21. Nau R, Gerber J, Bunkowski S, Bruck W. Axonal injury, a neglected cause of CNS damage in bacterial meningitis. Neurology. 2004;62(3):509-11.

22. Adams RD, Kubik CS, Bonner FJ. The clinical and pathological aspects of influenzal meningitis. Arch Pediatr. 1948;65(8):408-41.

23. Adams RD, Kubik CS, Bonner FJ. The clinical and pathological aspects of influenzal meningitis. Arch Pediatr 1948;65(7):354; passim.

24. Seele J, Beineke A, Hillermann LM, Jaschok-Kentner B, von PawelRammingen $U$, Valentin-Weigand $\mathrm{P}$, et al. The immunoglobulin $\mathrm{M}$ degrading enzyme of Streptococcus suis, IdeSsuis, is involved in complement evasion. Vet Res. 2015:46:45.

25. Seele J, Hillermann LM, Beineke A, Seitz M, von Pawel-Rammingen U, Valentin-Weigand $\mathrm{P}$, et al. The immunoglobulin M-degrading enzyme of Streptococcus suis, IdeSsuis, is a highly protective antigen against serotype 2. Vaccine. 2015:33(19):2207-12.

26. Baums CG, Kaim U, Fulde M, Ramachandran G, Goethe R, ValentinWeigand $P$. Identification of a novel virulence determinant with serum opacification activity in Streptococcus suis. Infect Immun. 2006; 74(11):6154-62

27. Tauber SC, Staszewski O, Prinz M, Weis J, Nolte K, Bunkowski S, et al. HIV encephalopathy: glial activation and hippocampal neuronal apoptosis, but limited neural repair. HIV Med. 2016:17(2):143-51.

28. Mattiesen WR, Tauber SC, Gerber J, Bunkowski S, Bruck W, Nau R. Increased neurogenesis after hypoxic-ischemic encephalopathy in humans is age related. Acta Neuropathol. 2009;117(5):525-34

29. Nau R, Zettl U, Gerber J, Trostdorf F, Michel U, Bottcher T, et al. Granulocytes in the subarachnoid space of humans and rabbits with bacterial meningitis undergo apoptosis and are eliminated by macrophages. Acta Neuropathol. 1998;96(5):472-80

30. Recher M, Malipiero U, Schaer DJ, Koedel U, Pfister HW, Birchler T, et al. Inhibition of meningitis-associated neutrophil apoptosis by TNF-alpha depends on functional PI3-kinase in monocytes. J Leukoc Biol. 2013; 93(2):259-66.

31. Tauber SC, Schlumbohm C, Schilg L, Fuchs E, Nau R, Gerber J. Intrauterine exposure to dexamethasone impairs proliferation but not neuronal differentiation in the dentate gyrus of newborn common marmoset monkeys. Brain Pathol. 2006:16(3):209-17.

32. Kreutzberg GW. Microglia: a sensor for pathological events in the CNS Trends Neurosci. 1996:19(8):312-8.

33. SanCristobal M, Chevalet C, Haley CS, Joosten R, Rattink AP, Harlizius B, et al. Genetic diversity within and between European pig breeds using microsatellite markers. Anim Genet. 2006;37(3):189-98.

34. Baums CG, Bruggemann C, Kock C, Beineke A, Waldmann KH, ValentinWeigand P. Immunogenicity of an autogenous Streptococcus suis bacterin in preparturient sows and their piglets in relation to protection after weaning. Clin Vaccine Immunol. 2010;17(10):1589-97. 
35. Staats JJ, Feder I, Okwumabua O, Chengappa MM. Streptococcus suis: past and present. Vet Res Commun. 1997;21(6):381-407.

36. Fauveau L, Mourtada Y, Hazouard E. Meningoencephalitis related-to Streptococcus suis in a butcher: relevance of occupational questionnaire at emergency room. Ann Fr Anesth Reanim. 2007;26(9):814-5.

37. Wongjittraporn S, Teerasukjinda O, Yee M, Chung HH. Streptococcus suis meningoencephalitis with seizure from raw pork ingestion: a case report. Hawaii J Med Public Health. 2014;73(9 Suppl 1):13-4.

38. Zheng P, Zhao YX, Zhang AD, Kang C, Chen HC, Jin ML. Pathologic analysis of the brain from Streptococcus suis type 2 experimentally infected pigs. Vet Pathol. 2009:46(3):531-5.

39. Sanford SE. Gross and histopathological findings in unusual lesions caused by Streptococcus suis in pigs. II Central nervous system lesions. Can J Vet Res. 1987;51(4):486-9.

40. Fittipaldi N, Sekizaki T, Takamatsu D, de la Cruz Dominguez-Punaro M, Harel $J$, Bui NK, et al. Significant contribution of the pgdA gene to the virulence of Streptococcus suis. Mol Microbiol. 2008;70(5):1120-35.

41. Fittipaldi N, Sekizaki T, Takamatsu D, Harel J, Dominguez-Punaro Mde L, Von Aulock S, et al. D-alanylation of lipoteichoic acid contributes to the virulence of Streptococcus suis. Infect Immun. 2008;76(8):3587-94.

42. de Greeff A, Buys H, Verhaar R, Dijkstra J, van Alphen L, Smith HE. Contribution of fibronectin-binding protein to pathogenesis of Streptococcus suis serotype 2. Infect Immun. 2002;70(3):1319-25.

43. Zhang A, Mu X, Chen B, Han L, Chen H, Jin M. IgA1 protease contributes to the virulence of Streptococcus suis. Vet Microbiol. 2011;148(2-4):436-9.

44. Reams RY, Glickman LT, Harrington DD, Thacker HL, Bowersock TL. Streptococcus suis infection in swine: a retrospective study of 256 cases. Part II. Clinical signs, gross and microscopic lesions, and coexisting microorganisms. J Vet Diagn Investig. 1994;6(3):326-34.

45. Seitz M, Beineke A, Seele J, Fulde M, Valentin-Weigand P, Baums CG. A novel intranasal mouse model for mucosal colonization by Streptococcus suis serotype 2. J Med Microbiol. 2012;61(Pt 9):1311-8.

46. Loeffler JM, Ringer R, Hablutzel M, Tauber MG, Leib SL. The free radical scavenger alpha-phenyl-tert-butyl nitrone aggravates hippocampal apoptosis and learning deficits in experimental pneumococcal meningitis. J Infect Dis. 2001:183(2):247-52

47. Gerber J, Bottcher T, Bering J, Bunkowski S, Bruck W, Kuhnt U, et al. Increased neurogenesis after experimental Streptococcus pneumoniae meningitis. J Neurosci Res. 2003;73(4):441-6.

48. Tauber SC, Eiffert H, Kellner S, Lugert R, Bunkowski S, Schutze S, et al. Fungal encephalitis in human autopsy cases is associated with extensive neuronal damage but only minimal repair. Neuropathol Appl Neurobiol. 2014:40(5):610-27.

49. Tauber SC, Bunkowski S, Bruck W, Nau R. Septic metastatic encephalitis: coexistence of brain damage and repair. Neuropathol Appl Neurobiol. 2011; 37(7):768-76.

50. Leib SL, Kim YS, Ferriero DM, Tauber MG. Neuroprotective effect of excitatory amino acid antagonist kynurenic acid in experimental bacterial meningitis. J Infect Dis. 1996;173(1):166-71.

51. Ostergaard C, Leib SL, Rowland I, Brandt CT. Bacteremia causes hippocampal apoptosis in experimental pneumococcal meningitis. BMC Infect Dis. 2010;10(1)

52. Zweigner J, Jackowski S, Smith SH, Van Der Merwe M, Weber JR, Tuomanen El. Bacterial inhibition of phosphatidylcholine synthesis triggers apoptosis in the brain. J Exp Med. 2004:200(1):99-106.

53. Stringaris AK, Geisenhainer J, Bergmann F, Balshusemann C, Lee U, Zysk G, et al. Neurotoxicity of pneumolysin, a major pneumococcal virulence factor, involves calcium influx and depends on activation of p38 mitogen-activated protein kinase. Neurobiol Dis. 2002;11(3):355-68.

54. Jacobs AA, Loeffen PL, van den Berg AJ, Storm PK. Identification, purification, and characterization of a thiol-activated hemolysin (suilysin) of Streptococcus suis. Infect Immun. 1994;62(5):1742-8.

55. Niev Al, Stringaris AK, Nau R, Neumann H. Neuronal injury mediated via stimulation of microglial toll-like receptor-9 (TLR9). FASEB J. 2004;18(2):412-4.

56. Lehnardt S, Massillon L, Follett P, Jensen FE, Ratan R, Rosenberg PA, et al. Activation of innate immunity in the CNS triggers neurodegeneration through a toll-like receptor 4-dependent pathway. Proc Natl Acad Sci U S A. 2003:100(14):8514-9.

57. Dean JM, Wang X, Kaindl AM, Gressens P, Fleiss B, Hagberg H, et al. Microglial MyD88 signaling regulates acute neuronal toxicity of LPSstimulated microglia in vitro. Brain Behav Immun. 2010;24(5):776-83.
58. Hoffmann O, Braun JS, Becker D, Halle A, Freyer D, Dagand E, et al. TLR2 mediates neuroinflammation and neuronal damage. J Immunol. 2007; 178(10):6476-81.

59. Combs CK, Karlo JC, Kao SC. Landreth GE. Beta-amyloid stimulation of microglia and monocytes results in TNFalpha-dependent expression of inducible nitric oxide synthase and neuronal apoptosis. J Neurosci. 2001; 21(4):1179-88.

60. Schutze S, Loleit T, Zeretzke M, Bunkowski S, Bruck W, Ribes S, et al. Additive microglia-mediated neuronal injury caused by amyloid-beta and bacterial TLR agonists in murine neuron-microglia co-cultures quantified by an automated image analysis using cognition network technology. J Alzheimers Dis. 2012;31(3):651-7.

61. Prinz M, Kann O, Draheim HJ, Schumann RR, Kettenmann H, Weber JR, et al Microglial activation by components of gram-positive and -negative bacteria: distinct and common routes to the induction of ion channels and cytokines. J Neuropathol Exp Neurol. 1999;58(10):1078-89.

62. Lian D, He D, Wu J, Liu Y, Zhu M, Sun J, et al. Exogenous BDNF increases neurogenesis in the hippocampus in experimental Streptococcus pneumoniae meningitis. J Neuroimmunol. 2016;294:46-55.

63. Liebetanz D, Gerber J, Schiffner C, Schutze S, Klinker F, Jarry H, et al. Preinfection physical exercise decreases mortality and stimulates neurogenesis in bacterial meningitis. J Neuroinflammation. 2012;9:168.

64. Barichello T, Fagundes GD, Generoso JS, Dagostin CS, Simoes LR, Vilela MC, et al. Environmental enrichment restores cognitive deficits induced by experimental childhood meningitis. Rev Bras Psiquiatr. 2014;36(4):322-9.

65. Tauber SC, Ribes S, Ebert S, Heinz T, Fingerle V, Bunkowski S, et al. Long-term intrathecal infusion of outer surface protein $C$ from Borrelia burgdorferi causes axonal damage. J Neuropathol Exp Neurol. 2011; 70(9):748-57

66. de Greeff A, van Selm S, Buys H, Harders-Westerveen JF, Tunjungputri RN, de Mast $Q$, et al. Pneumococcal colonization and invasive disease studied in a porcine model. BMC Microbiol. 2016;16:102.

67. Gerber J, Pohl K, Sander V, Bunkowski S, Nau R. Rifampin followed by ceftriaxone for experimental meningitis decreases lipoteichoic acid concentrations in cerebrospinal fluid and reduces neuronal damage in comparison to ceftriaxone alone. Antimicrob Agents Chemother. 2003; 47(4):1313-7.

68. Nau R, Wellmer A, Soto A, Koch K, Schneider O, Schmidt H, et al. Rifampin reduces early mortality in experimental Streptococcus pneumoniae meningitis. J Infect Dis. 1999;179(6):1557-60.

\section{Ready to submit your research? Choose BMC and benefit from:}

- fast, convenient online submission

- thorough peer review by experienced researchers in your field

- rapid publication on acceptance

- support for research data, including large and complex data types

- gold Open Access which fosters wider collaboration and increased citations

- maximum visibility for your research: over $100 \mathrm{M}$ website views per year

At BMC, research is always in progress.

Learn more biomedcentral.com/submissions 